http://economix.fr

\title{
Expert opinion in a tort litigation game
}

Document de Travail

Working Paper 2016-23
Yves Oytana Nathalie Chappe

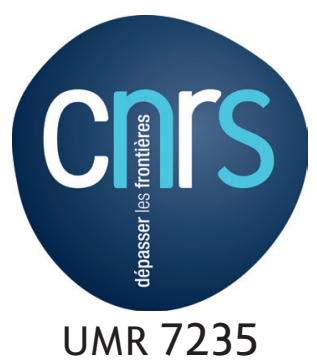

UMR 7235
Université de Paris Ouest Nanterre La Défense (bâtiment G) 200, Avenue de la République 92001 NANTERRE CEDEX université

Paris Ouest

Nanterre La Défense 


\title{
Expert opinion in a tort litigation game
}

\author{
Yves Oytana* Nathalie Chappe ${ }^{\dagger}$
}

June 21, 2016

\begin{abstract}
We investigate the potential impact of various proposed reforms intended to improve the quality of expert testimony while reducing its cost, and to facilitate the work of judges in appointing experts and reading their reports. To do so, we present a unilateral care model under strict liability in which the court cannot perfectly observe the amount of harm a tortfeasor has caused to a victim. However, the judge may appoint an expert to improve his chance of reaching a correct decision. In this context, we find that the likelihood of a victim filing a lawsuit decreases with the quality of the expert testimony and with the cost of the expertise procedure, and increases with the non-monetary cost for the judge to appoint an expert. Moreover, we find that the effects of these parameters on the injurer's level of precaution are ambiguous. We also find that the injurer's level of care is suboptimal. Finally, we make some public policy recommendations in order to (i) increase the injurer's level of care and (ii) reduce the expected cost of a trial in the event of an accident. We find that the policy maker faces a trade-off between these two objectives.
\end{abstract}

Keywords: Litigation, Expert, Expert testimony, Liability.

JEL codes: K40, K41, K49.

*EconomiX, Paris West University Nanterre La Défense; 200, Avenue de la République, 92001 Nanterre, France.

†CRESE, University of Franche-Comté; 45, Avenue de l'Observatoire, 25030 Besançon, France. We would like to thank Marie Obidzinski. 
"Quand on paie des experts aux tarifs d'une femme de ménage, on a des expertises de femme de ménage."

"When you pay experts at cleaners' rates, what you get are cleaners' appraisals."

\section{Introduction}

Motivation. This quote from the expert psychologist Jean-Luc Viaux during the Outreau trial (a highly publicized French criminal case), prompted much debate about expert testimony. Although Outreau was a criminal case (about sexual abuse of minors), the malfunctions observed cast doubt on how effective expert testimony is, even in civil trials. The outcome was a 2011 report by the committee on judicial expert appraisals ${ }^{1}$. The committee responsible for this report stressed two crucial issues about the use of expert proceedings in civil matters concerning the influence of expert testimony on access to and the quality of the judicial system.

Expert testimony has become increasingly used in civil trials although it may greatly jeopardize victims' access to justice by increasing procedural delays and by generating additional costs. Consequently, it is recommended to appoint an expert only in cases that are particularly technical and for which the information provided by the expert is crucial to the

\footnotetext{
${ }^{1}$ Rapport de la commission de réflexion sur l'expertise (2011).
} 
judge's decision-making. Moreover, the proper administration of justice (i.e. the quality of the judicial system) is not ensured when courts have no accurate information about an expert's workload, availability, and competence at the time they are designated. Maintaining registered public lists of certified experts ensures a minimum level of competence of the experts appointed. However, there remains scope for significant improvement.

These concerns lead us to ask how expert testimony in civil litigation can be improved upon?

As noted by the Advisory Committee on rule 702 of the US Federal Rules of Evidence, ${ }^{2}$ "An intelligent evaluation of facts is often difficult or impossible without the application of some scientific, technical, or other specialized knowledge. The most common source of this knowledge is the expert witness, although there are other techniques for supplying it." The importance of expert witnesses (and in particular of economic expert witnesses) has also been pointed out by Posner (1999) in a symposium on economists as expert witnesses (see also Thornton and Ward (1999) and Mandel (1999)).

In tort law, damages may be awarded to restore an injured party to the position she was

\footnotetext{
${ }^{2}$ Rule 702 states that:
}

A witness who is qualified as an expert by knowledge, skill, experience, training, or education may testify in the form of an opinion or otherwise if:
(a) the expert's scientific, technical, or other specialized knowledge will help the trier of fact to understand the evidence or to determine a fact in issue;
(b) the testimony is based on sufficient facts or data;
(c) the testimony is the product of reliable principles and methods; and
(d) the expert has reliably applied the principles and methods to the facts of the case. 
in before being harmed. It may be difficult for the judge (court) to determine the level (amount) of damages. However, in order to help him assess the level of economic damages, he has the possibility of appointing an expert. In addition, in cases in which an accident may have caused substantial damages which are not directly observable by the judge, it may be difficult for the judge to forego (do without) the expert's knowledge of how to collect and use various data and to compute damages. ${ }^{3}$ Indeed, it may be complicated for the judge to assess damages if he has to evaluate economic damages ${ }^{4}$ (for example past and future lost wages, medical bills, etc.) and/or non-economic damages ${ }^{5}$ (the psychological cost of an incapacitating injury, damaged reputation, etc.). Many questions then arise for the judge, regarding in particular the methodology he should use for example to evaluate the expected loss of the victim's future income (evaluating the duration of such losses may also be particularly difficult), the cost associated with physical and psychological pain and suffering, the interest rate that should be used to discount the victim's losses, etc. The judge is not always well equipped to answer theses questions. Thus, he may choose to leave them to a court-appointed economic expert.

Given the needs and the major issues surrounding expert testimony in France, several areas of improvement are highlighted in the report by the committee on judicial expert appraisals (2011). Among these recommendations, a number of instruments are singled out that may

\footnotetext{
${ }^{3}$ This is the case for example if the judge has to evaluate environmental damages.

${ }^{4}$ Economic damages are defined as the compensation received in place of any money lost due to an accident.

${ }^{5}$ In comparison to economic damages, non-economic damages are more abstract and are often referred to as "pain and suffering".
} 
have a positive impact on the quality of and accessibility to the legal system.

A first instrument is to improve the quality of expert testimony. This quality may be influenced by the training of experts, the way they are selected, and their ethics. In France, in order to improve the quality of expert testimony, Law No. 2004-130 of 11 February 2004 and its implementing decree No. 2004-1463 of 23 December 2004 sets more stringent criteria for the selection of experts who appear on the registered public lists, in order to better ascertain their level of skill, with a longer probatory period. However, for the committee on judicial expert appraisals (2011), these laws are not sufficient, in particular since "the disparity among procedures for selecting and appointing experts depending on the nature of litigation (civil, criminal, and administrative) makes the choice of expert less reliable" ${ }^{6}$ Moreover, there is room for improving the quality of expert testimony, for instance by providing the same basic training for all registered experts and maintaining scorecards for each expert (with criteria such as relevance, clarity, respect of deadlines and accuracy of the answers) that can be used by the trial court.

A second instrument is to improve the judge's access to the expertise procedure, in order to facilitate his investigative work. Currently, the establishment of lists of approved experts is governed by Law No 71-498 of 29 June 1971 and decree No. 73-1184 of 31 December 1974. A single list is held by each appeal court. In addition, the Cour de Cassation registry holds

\footnotetext{
6 "L'éparpillement des modalités de sélection et désignation des experts selon la nature des contentieux (civil, pénal, administratif) fragilise la fiabilité du choix de l'expert."
} 
a national list. These lists classify experts by their specialities. But, here too, areas for improvement exist. One recommendation is to harmonize the rules governing the selection and appointment of experts, especially when they are not chosen from a list of accredited experts (since the use of these lists is optional in civil matters). ${ }^{7}$ Moreover, these lists of experts could be significantly improved, for example by developing national databases of registered experts in order to ensure improved monitoring of experts (and to facilitate this monitoring by providing appropriate training to judges). Finally, resort to expert testimony could be facilitated by using a standard expert's report form, to avoid reports that are too long and/or technical for the judge and parties to fully understand.

A third instrument is the reduction of the cost associated with the expertise proceedings. An expert procedure leads to potentially extensive delays forcing the parties to bear additional costs. Indeed, the effect of delays is far from negligible, since the average length of an expertise is 15.3 months, and reaches 20.2 months in the construction sector. Furthermore, the average cost of a civil expert testimony is 2,174 euros rising to 3,475 euros in the construction sector. ${ }^{8}$ Accordingly, in civil cases, the costs associated with expert testimony may hinder the access to justice for some victims with a too high level of income to be eligible for legal aid services. In order to limit the costs and delays of expertise, one possibility is to make greater use of faster and cheaper investigative measures, such as expert's consultations or expert's observations. Another solution might be to limit the use of expert testimony to

\footnotetext{
${ }^{7} \mathrm{~A}$ concrete proposal, going in this direction and made by the committee on judicial expert appraisals, is to add a requirement that the decision to appoint an expert not registered on a list of approved experts must be justified.

${ }^{8}$ See the statistics in "Infostat Justice" (May 2003).
} 
cases where the stakes are sufficiently high.

Contribution. In this paper, we present a unilateral care model under strict liability in order to study the efficiency of these three instruments (the quality of expert testimony, the judge's accessibility to the expertise procedure, the reduction of costs associated with the expertise proceedings). We investigate how they may affect (i) the decision of victims to sue in the event of an accident (and thus the accessibility to justice) and (ii) the level of care chosen by a potential injurer. We then compare the injurer's level of care with that minimizing the total expected cost, which we define as the sum of the injurer's cost of care, the expected cost of trials (which we assume is equal to the expected cost of expert testimony) and the expected harm suffered by victims. Finally, we make some public policy recommendations and extend the model to allow for the possibility of settlement before the victim decides whether or not to sue. Indeed, a settlement stage is often included in standard litigation models (see Shavell (1982), Rubinfeld and Polinsky (1988) and Bebchuk (1984) among others). It is thus important to determine how our results are affected when we include the possibility for the parties to settle rather than litigate.

Summary of the model. In our model, an injurer (he) first chooses his level of care, knowing that the probability of an accident decreases with care. We focus on a unilateral care model, so the victim (she) cannot influence the probability of an accident. However, if an accident does occur, she decides whether or not to sue. Victims are heterogeneous with 
respect to the harm they suffer in the event of an accident and, if a victim decides to sue, then the judge decides whether or not to appoint an expert, and then chooses the amount of damages to be awarded.

In order to focus on the specific topic of the evaluation of damages, we assume that strict liability applies. Thus, the expert's only role is to bring information to the judge about the level of harm suffered by the victim. He is not tasked with determining whether or not the injurer was negligent. Moreover, we focus on the case in which the expert is courtappointed. We do not consider the case in which the expert is a "hired gun", selected by a party. ${ }^{9}$ In the context of our model, the probability of the judge awarding the correct amount of compensation to the victim increases when an expert is appointed by the judge. However, an expertise procedure is costly. These costs are shared between the plaintiff (the victim) and the defendant (the injurer), and we allow for a continuum of cost-sharing rules, from a pro-plaintiff rule (the cost is borne solely by the injurer) to a pro-defendant one (the cost is borne solely by the victim).

Main results. First, we show that the probability of a victim filing a lawsuit decreases with the cost of the expert testimony (our first instrument) and the quality of the expert testimony (our second instrument), and increases with the (non-monetary) cost for the judge to appoint an expert ${ }^{10}$ (our third instrument). The results regarding the quality of the expert

\footnotetext{
${ }^{9}$ See for example Turner (2006) and Patterson (1999) for discussions on the subject of hired guns in medical malpractice cases.

${ }^{10}$ This (non-monetary) cost may be interpreted as the cost associated with a longer period of procedure
} 
testimony and the (non-monetary) cost for the judge to appoint an expert may be surprising at first glance. Indeed, one might well expect that the probability of lawsuit in the event of an accident should increase with the quality of expert testimony and decrease with the (non-monetary) cost for the judge to appoint an expert. However, in our model, we assume that the judge is a Bayesian decision-maker, which implies that even when he makes an error (i.e. when he does not observe the harm suffered by the victim), his expectation of damages (and thus his decision) is correct on average. Consequently, for the marginal victim (the victim who is indifferent between filing a lawsuit or not), the judge's decision when he fails to award the correct amount is biased upward. Thus, when no expert is appointed, the marginal victim's compensation is higher than when an expert is appointed. In other words, when an expert is less often appointed, which arises for example if the quality of the expertise decreases and/or the non-monetary cost of the expertise for the judge increases, the payoff of the marginal victim from filing a lawsuit increases: the proportion of victims willing to go to trial in the event of an accident increases.

Second, regarding the injurer's level of care at the equilibrium, we show that an increase in the quality of expertise has two effects. On one side, the judge is more likely to appoint an expert thereby increasing the expected cost of a trial for the injurer. On the other side, the probability of a trial in the event of an accident decreases. The overall effect on the injurer's expected cost and thus on his level of care is ambiguous. Similar reasoning applies regarding if the judge appoints an expert, the monitoring cost of the expert's investigations, the effort needed to read and understand his report, etc. 
the non-monetary cost of the expertise for the judge. We also find that an increase in the cost of expert testimony has an ambiguous effect on the injurer's expected cost in the event of an accident (and thus on his level of care): on one side, fewer victims lawsuits, but on the other side the injurer's expected cost of trial increases.

Third, we find that the level of care of the injurer at the equilibrium is suboptimal. However, assuming that the policy maker's objective is to reduce the total expected cost for both the injurer and the victim, we find that he often faces a trade-off between (i) increasing the injurer's level of care (to close the gap with the socially optimal level of care) and (ii) decreasing the probability of trials and thus the associated expected expertise costs in the event of an accident. Thus, we cannot make clear-cut public policy recommendations. Instead, we show that the optimal policy largely depends on what the policy maker's main objective is: giving the right incentives to the injurer versus reducing the expected cost of trials.

Related literature. Many papers focus on expert testimony in a broad sense. An important strand of this literature is that initiated by Crawford and Sobel (1982). Their cheap talk model has been extended in various ways (see for example Farrell (1993), Krishna and Morgan (2001), Ottaviani and Sorensen (2006)). In contrast to these papers, we focus on costly investigative measures such that delivering information to the judge about the amount of harm suffered by the victim is not cheap talk. Many contributions have also investigated the existing delegation relationship between the expert (the agent) and the decision-maker 
(the principal), by explicitly modeling their respective objectives and therefore the potential conflicts of interest arising between them (e.g. Bourjade and Jullien (2011), Morris (2001), Sobel (1985)). Unlike these papers, we do not deal with the expert's objectives. We model the judge's decision to hire an expert, but not the principal-agent relationship between them, concentrating instead on the injurer's level of care and the victim's decision to sue. Another important branch of the literature on expert testimony focuses on the comparison between the inquisitorial and the adversarial procedure (see Block et al. (2000), Dewatripont and Tirole (1999), Froeb and Kobayashi (2001)). ${ }^{11}$ For our part, we assume that only the judge may engage an expert: the investigations are centralized by the judge, and the investigative procedure is therefore inquisitorial. Another important issue in the literature on expert testimony is the use of multiple experts to improve the quality and the revelation of information (Gromb and Martimort (2007), Li (2010)). In our model, we assume that the choice of the judge is limited to appointing an expert or not. When he hires an expert, the probability of reaching a fair decision increases by a given amount (which depends on the relative quality of expert testimony).

Other papers have focused more specifically on the use of expert testimony in a judicial context (see Cecil and Willging (1993), Lambert and Oytana (2016), Oytana (2014), Tomlin and Cooper (2008), Yee (2008)). However, none of them addresses the issue of the ex ante impact on the parties of the possibility of the judge appointing an expert. This is what we

\footnotetext{
${ }^{11}$ On this subject, see also the contributions of Deffains and Demougin (2008), Palumbo (2001), Palumbo (2006), Parisi (2002), and Shin (1994).
} 
attempt to do in this paper by using a model à la Bebchuk (1984). Nonetheless, our model is different on a number of points. To begin with, the private information of the victim relates to the magnitude of harm that she has suffered and not to the likelihood of the plaintiff prevailing at trial. Moreover, in the model used by Bebchuk (1984) (as in most papers on dispute resolution), the compensation awarded to the victim by the judge is always correct. We relax this assumption to include the possibility of the judge making a mistake. Last but not least, Bebchuk (1984) is mainly interested in the settlement stage, whereas our main concern is on the impact on the parties' behavior of the possibility of the judge appointing a neutral expert in order to make better decisions about the amount of damages. On these last two points, our paper is also linked to the literature studying tort litigation when judicial errors may arise (Hylton (1990), Png (1986), Polinsky and Shavell (1989)). Note however that, unlike theses contributions, we do not deal with errors in causation but in the amount of damages alone.

Summary of the paper. The rest of this paper is organized as follows. In section 2, we present the model. In section 3 , we describe the equilibrium of our model. In section 4 , we give some comparative statics results regarding the proportion of victims who decide to sue following an accident, and the level of care of the injurer. We make some public policy recommendations in section 5. Section 6 extends our model to allow for the possibility of settlement. Section 7 contains concluding remarks. 


\section{The model}

Basic notation. A court has to decide a case under a strict liability regime. The trial follows from an accident in which the defendant is the injurer (he) and the plaintiff is the victim (she). The model assumes one potential injurer and a continuum of victim types, indexed by the amount of harm suffered in the event of an accident, denoted $L$, and distributed according to a distribution $G$ with differentiable density $g$ and support $[0, \bar{L}]$, such that $g(L) \neq 0$ for all $L \in(0, \bar{L})$. The amount $L$ is known to the plaintiff, but is not observable by the judge or the defendant.

The judge is tasked with determining the amount of compensation that will be awarded to the victim. His decision is right if and only if the damages awarded correspond to the victim's type $(L)$. As the actual amount of harm suffered by the victim may not be directly observable by the judge, he has the possibility of appointing a judicial expert to help him find evidence. If the judge does not appoint an expert, he has a probability of $q \in(0,1)$ of accurately ascertaining the victim's type. If he decides to appoint an expert, he has a probability of $p \in(0,1)$ of accurately ascertaining the victim's type. We assume that $p>q$. In other words, the judge is more likely to properly determine the victim's type if he appoints an expert. Moreover, if he decides to appoint an expert, the judge incurs a non-monetary cost $k>0$. This cost may represent, for example, the longer delay before the trial due to the expertise procedure, but also the cost of the personal effort made by the judge to search for a competent expert, to monitor the expert's investigations, to read and understand his 
report, etc.

We assume there is a continuum of judges who differ by their concern for the quality of judicial decision-making. More specifically, judges are indexed by the payoff they obtain if a correct decision is made. This payoff is denoted $\Delta$ and is distributed according to a distribution $F$ with differentiable density $f$ and support $[0,+\infty),{ }^{12}$ such that $f(\Delta) \neq 0$ for all $\Delta \in[0,+\infty)$.

In order to focus on the consequences of the possibility for the judge appointing an expert, we assume that the only litigation costs are those related to the expertise procedure, denoted by $c_{e} \geq 0$. We define the parameter $\alpha \in[0,1]$ as being the share of the cost $c_{e}$ which is borne by the injurer. Thus, if $\alpha=\frac{1}{2}$, the litigation costs are borne equally by each litigant. If $\alpha=0$ (respectively $\alpha=1$ ), the litigation costs are borne solely by the victim (respectively the injurer).

\section{Timing of the game.}

$\mathbf{t}=\mathbf{0}$. Nature chooses the victim's type $(L)$.

$\mathbf{t}=1$. The potential injurer chooses his level of care $x$ at cost $c(x)$, with $c^{\prime}(x)>0$ and $c^{\prime \prime}(x)>0$. With probability $\pi(x)$ (respectively $1-\pi(x)$ ), an accident occurs (respectively there is no accident), with $\pi^{\prime}(x)<0$ and $\pi^{\prime \prime}(x)>0$.

$\mathbf{t}=2$. If an accident occurs, the victim decides whether or not to sue.

\footnotetext{
${ }^{12} \mathrm{~A}$ support $[0,+\infty)$ allows us to focus on the (more realistic) situation in which there is always a positive proportion of judges who decide to appoint a neutral expert, although judges do not systematically hire an expert.
} 
$\mathbf{t}=\mathbf{3}$. If the victim files a lawsuit, the judge decides whether or not to appoint an expert and makes a decision $y \in[0, \bar{L}]$ regarding the compensation the injurer has to pay to the victim.

We do not include any settlement stage. The possibility the parties will settle rather than litigate will be discussed later in section 6 . We solve this game by backward induction and describe the equilibrium in the next section.

\section{Resolution}

In this section, we first determine the amount of compensation (depending on whether the judge has observed the victim's type or not) and the judge's decision to appoint an expert. We then study the decision of the victim whether or not to sue. Finally, we solve for the injurer's level of care.

\subsection{Compensation and judge's decision to appoint an expert}

The victim's compensation. The judge's decision depends on whether he observes the victim's type or not. If the judge does (respectively does not) appoint an expert, then he has a probability of $p$ (respectively $q$ ) of accurately ascertaining the victim's type, and makes a correct decision $y=L$. If he does not correctly ascertain the victim's type, the judge makes an incorrect decision: the compensation in this case is specified below. 
If he does not correctly ascertain the victim's type, the judge revises his belief, ${ }^{13}$ taking into account the fact that a victim who has suffered harm below a certain threshold $(L \leq \hat{L})$ will decide not to file. ${ }^{14}$ For a given $\hat{L}$, the judge's belief that the magnitude of harm caused by the defendant takes a specific value $L_{i}\left(\right.$ with $\left.L_{i}>\hat{L}\right)$ is:

$$
\operatorname{Pr}\left(L=L_{i} \mid \hat{L}\right)=\frac{g\left(L_{i}\right)}{1-G(\hat{L})}
$$

The judge's decision, when he has no information on the magnitude of harm suffered by the victim, is thus:

$$
y(\hat{L})=\int_{\hat{L}}^{\bar{L}} \frac{L}{1-G(\hat{L})} d G(L)
$$

Recall that, prior to the trial, only the victim knows the amount of harm, while the injurer and the judge observe only the occurrence of an accident and the distribution of damages among the population of victims. The judge knows that a victim only files a lawsuit if her type (the damage she suffers) is sufficiently important, with $L>\hat{L}$. As a Bayesian decisionmaker, the judge's decision regarding the level of compensation is thus equal to the average damage incurred by the victims who decide to sue in the event of an accident.

The judge's decision to appoint an expert. The judge's utility function is given by his expected payoff from a correct decision, less his non-monetary cost $(k)$ if he decides to appoint an expert (the cost of the effort for the judge to select an expert, to monitor the

\footnotetext{
${ }^{13}$ We thus assume that the judge is a Bayesian decision-maker.

${ }^{14}$ Note that $\hat{L}$ is an endogenous variable to be determined. Also, we discuss later the situations in which all cases go to trial $(\hat{L}<0)$, or no case goes to $\operatorname{trial}(\hat{L} \geq \bar{L})$.
} 
investigations, to read and understand the expert's report, etc.). Knowing that the judge makes a correct decision only if he observes the victim's type, his utility function is given by:

$$
U_{j}= \begin{cases}p \Delta-k & \text { if he decides to appoint an expert } \\ q \Delta & \text { otherwise }\end{cases}
$$

From this, we find that the judge does not appoint an expert if his payoff from a correct decision is no more than a threshold, i.e. if:

$$
\Delta \leq \frac{k}{p-q}:=\hat{\Delta}
$$

Somewhat intuitively, the judge is more willing to appoint an expert when the payoff he obtains in the event he makes a correct decision $(\Delta)$ is high, ${ }^{15}$ his cost from appointing an expert $(k)$ is low, the quality of the expertise $(p)$ is high, and the probability of a correct decision being made if he does not appoint an expert $(q)$ is low.

All judges for whom the expected payoff from a correct decision is strictly above the threshold $\hat{\Delta}$ decide to appoint an expert. The proportion of judges who choose to appoint an expert is thus $1-F(\hat{\Delta})$.

\footnotetext{
${ }^{15}$ The parameter $\Delta$ may stand, for example, for the preoccupation of the judge for his reputation if there is a higher probability that his decision is reversed in appeal when incorrect. This parameter may also capture the intrinsic preoccupation of the judge for the quality of his decision-making.
} 


\subsection{Victim's decision to sue}

Recall that if the victim decides to sue and the judge does (respectively does not) appoint an expert, the victim obtains a compensation $L$ with probability $p$ (respectively $q$ ), and $y(\hat{L})$ with probability $1-p$ (respectively $1-q$ ). Moreover, if the judge decides to appoint an expert, the victim bears an additional cost $(1-\alpha) c_{e}$. The harm being a sunk cost at the time the victim decides whether or not to sue, her expected payoff is 0 if she does not file. Thus, she decides to sue if:

$$
F(\hat{\Delta})(q L+(1-q) y(\hat{L}))+(1-F(\hat{\Delta}))\left(p L+(1-p) y(\hat{L})-(1-\alpha) c_{e}\right)>0
$$

The first term on the left side of this inequality is the expected payoff of the victim if she files a lawsuit and the judge does not hire an expert. The second term is her expected payoff if the judge hires an expert. The marginal victim payoff (i.e. the payoff of the victim of type $\hat{L}$ ) decreases with the probability an expert is appointed, because (i) she incurs a share $(1-\alpha)$ of the cost of expertise and (ii) the expected compensation she obtains decreases. ${ }^{16}$ Depending on the value of the parameters, we observe that there are three possibilities: no case goes to trial, all cases go to trial, and only a fraction of cases go to trial. The level of care chosen by the injurer in each of these cases is given in the next subsection. ${ }^{17}$

\footnotetext{
${ }^{16}$ Her expected compensation is higher if the judge does not observe her type because $\left.y(\hat{L})>\hat{L}\right)$.

${ }^{17}$ If no case goes to trial, condition (5) is never satisfied, even for a victim of type $L=\bar{L}$. If all cases go to trial, condition (5) is always satisfied, even for a victim of type $L=0$. Finally, if only a fraction of cases goes to trial, then there exists $\hat{L} \in[0, \bar{L}]$ defined by:

$$
F(\hat{\Delta})(q \hat{L}+(1-q) y(\hat{L}))+(1-F(\hat{\Delta}))\left(p \hat{L}+(1-p) y(\hat{L})-(1-\alpha) c_{e}\right)=0
$$
}

We focus mainly on this third case in the remainder of this paper. 


\subsection{Care choice by the injurer}

No case goes to trial. If no victim goes to trial, the potential injurer has no incentive to increase his level of care. The cost-minimizing level of care is given by $x_{n}^{*}=0$, and the probability of an accident is $\pi(0)$.

All cases go to trial. If all victims go to trial, the expected cost for the potential injurer when he chooses his level of care is:

$$
c(x)+\pi(x)\left[(1-F(\hat{\Delta})) \alpha c_{e}+\int_{0}^{\bar{L}} L d G(L)\right]
$$

To understand this expression, recall that the harm suffered by the victim $(L)$ is her private information. The term $\int_{0}^{\bar{L}} L d G(L)$ represents the victim's expected compensation from the point of view of the potential injurer. ${ }^{18}$ Minimizing (6) with respect to $x$ yields the following first order condition:

$$
c^{\prime}\left(x_{a}^{*}\right)+\pi^{\prime}\left(x_{a}^{*}\right)\left[(1-F(\hat{\Delta})) \alpha c_{e}+\int_{0}^{\bar{L}} L d G(L)\right]=0
$$

Note that the behavior of the potential injurer at the time he chooses his level of care is influenced by the possibility that the judge will appoint an expert only through the expected

\footnotetext{
${ }^{18}$ Note that:

$$
\int_{0}^{\bar{L}} L d G(L)=\int_{0}^{\bar{L}} F(\hat{\Delta})(q L+(1-q) y(0))+(1-F(\hat{\Delta}))(p L+(1-p) y(0)) d G(L)
$$
}


cost of the expert testimony in the event of an accident. When all cases go to trial, the fact that appointing an expert allows the judge to make a better decision has no impact on the injurer's level of care.

Only a fraction of cases go to trial. We now turn to the most interesting situation in which only some of the victims go to trial. The expected cost for the potential injurer is:

$$
C_{i}=c(x)+\pi(x)(1-G(\hat{L}))\left[(1-F(\hat{\Delta})) \alpha c_{e}+y(\hat{L})\right]
$$

Using the same reasoning as in the situation in which all cases go to trial, we know that $y(\hat{L})$ is the expected damages the injurer has to pay in the event of a trial, at the time he decides on his level of care. Minimizing (8) with respect to $x$ yields the following first order condition:

$$
\frac{\partial C_{i}}{\partial x}=c^{\prime}\left(x^{*}\right)+\pi^{\prime}\left(x^{*}\right)(1-G(\hat{L}))\left[(1-F(\hat{\Delta})) \alpha c_{e}+y(\hat{L})\right]=0
$$

This first order condition equals the marginal cost of care for the injurer with his marginal benefit related to the decrease in the expected cost of expertise and compensation in the event of an accident.

We have now fully characterized the model's equilibrium. The next section presents some comparative statics results. 


\section{Comparative statics}

In this section, we study the impact of a variation in the parameters corresponding to the three instruments highlighted in the introduction, on the proportion of victims who sue in the event of an accident (measuring the accessibility to the courts) and on the injurer's level of care. In a first subsection, we study the effect of an increase in the quality of the expert testimony (first instrument). In a second subsection, we study the effect of an increase in the non-monetary cost of an expert testimony for the judge (second instrument). In a third subsection, we study the effect of an increase in the cost of expert testimony incurred by the parties (third instrument).

Unless otherwise specified, we focus hereafter on the case in which only some victims sue. ${ }^{19}$

\subsection{First instrument: the quality of expert testimony}

Proposition 1. An increase in $p$ decreases the proportion of victims who sue, and has an ambiguous effect on the injurer's level of care.

Proof. The threshold $\hat{L}$ is the solution of:

$$
\begin{aligned}
U_{v}(\hat{L})=F(\hat{\Delta})(q \hat{L}+(1-q) & y(\hat{L})) \\
& +(1-F(\hat{\Delta}))\left(p \hat{L}+(1-p) y(\hat{L})-(1-\alpha) c_{e}\right)=0
\end{aligned}
$$

\footnotetext{
${ }^{19}$ Recall that in this equilibrium the level of care is given by equation (9) and the proportion of victims who go to trial is $1-G(\hat{L}) \in(0,1)$.
} 
We have:

$$
\frac{\partial U_{v}}{\partial \hat{L}}=F(\hat{\Delta})\left(q+(1-q) y^{\prime}(\hat{L})\right)+(1-F(\hat{\Delta}))\left(p+(1-p) y^{\prime}(\hat{L})\right)
$$

It is straightforward from $(2)$ that $y^{\prime}(\hat{L})>0$ and, as a consequence, that we have $\frac{\partial U_{v}}{\partial \hat{L}}>0$. Moreover, we have:

$$
\frac{\partial U_{v}}{\partial p}=(1-F(\hat{\Delta}))(\hat{L}-y(\hat{L}))+\frac{\partial F}{\partial \hat{\Delta}} \frac{\partial \hat{\Delta}}{\partial p}\left[(p-q)(y(\hat{L})-\hat{L})+(1-\alpha) c_{e}\right]
$$

We know that $\frac{\partial F}{\partial \hat{\Delta}}>0, \frac{\partial \hat{\Delta}}{\partial p}<0, q<p$ and $\hat{L}<y(\hat{L})$. Consequently, we have $\frac{\partial U_{v}}{\partial p}<0$. From the implicit function theorem, we know that the sign of $\frac{\partial \hat{L}}{\partial p}$ is the inverse of the sign of $\frac{\partial U_{v}}{\partial p}$. In other words, we have $\frac{\partial \hat{L}}{\partial p}>0$ : the number of cases going to trial decreases with $p$.

Recall that the cost the injurer minimizes is:

$$
\begin{aligned}
C_{i} & =c(x)+\pi(x)(1-G(\hat{L}))\left((1-F(\hat{\Delta})) \alpha c_{e}+y(\hat{L})\right) \\
& =c(x)+\pi(x)\left[(1-G(\hat{L}))(1-F(\hat{\Delta})) \alpha c_{e}+\int_{\hat{L}}^{\bar{L}} L d G(L)\right]
\end{aligned}
$$

The second order condition for the minimization of this cost is:

$$
\frac{\partial^{2} C_{i}}{\partial x^{2}}=c^{\prime \prime}(x)+\pi^{\prime \prime}(x)\left[(1-G(\hat{L}))(1-F(\hat{\Delta})) \alpha c_{e}+\int_{\hat{L}}^{\bar{L}} L d G(L)\right]>0
$$


Moreover, we have:

$$
\frac{\partial^{2} C_{i}}{\partial x \partial p}=-\frac{\partial G}{\partial \hat{L}} \frac{\partial \hat{L}}{\partial p} \pi^{\prime}(x)\left[(1-F(\hat{\Delta})) \alpha c_{e}+\hat{L}\right]-\frac{\partial F}{\partial \hat{\Delta}} \frac{\partial \hat{\Delta}}{\partial p} \pi^{\prime}(x)(1-G(\hat{L})) \alpha c_{e}
$$

The sign of this expression is ambiguous: an increase in $p$ has an ambiguous effect on the injurer's level of care.

The intuition for the result stating that an increase in $p$ decreases the proportion of victims who sue is the following. First, a higher $p$ increases the probability of the judge appointing an expert, thus increasing the expected cost of the expertise for the victim in case of a trial. Second, it increases the probability of the marginal victim obtaining $\hat{L}$ instead of $y(\hat{L})$. But we know that $\hat{L}<y(\hat{L})$ : when the judge does not appoint an expert, the marginal victim obtains higher compensation. Combining these two effects, the more frequent appointment of an expert due to the increase in $p$ triggers an increase in the expected cost of the trial due to a higher expected expert appraisal cost and reduces the expected compensation for the marginal victim. A lawsuit is less interesting for her: the accessibility of justice for the victim is weakened.

The intuition for the result stating that an increase in $p$ has an ambiguous effect on the level of precaution of the injurer is the following. On the one hand, a higher $p$ decreases the expected compensation and decreases the expected cost of expertise because fewer victims file a lawsuit, reducing the incentive of the injurer to take care. On the other hand, an expert is more often appointed in the event of a trial, and thus the expected cost of the expertise 
increases, increasing the incentive of the injurer to take care. Depending on which effect dominates, the injurer will raise or lower his level of care.

More formally, note that which effect dominates depends crucially on the size of $\left|\frac{\partial G}{\partial \hat{L}} \frac{\partial \hat{L}}{\partial p}\right|$ relative to $\left|\frac{\partial F}{\partial \hat{\Delta}} \frac{\partial \hat{\Delta}}{\partial p}\right|$. More specifically, if $\left|\frac{\partial G}{\partial \hat{L}} \frac{\partial \hat{L}}{\partial p}\right|$ is sufficiently important relative to $\left|\frac{\partial F}{\partial \hat{\Delta}} \frac{\partial \hat{\Delta}}{\partial p}\right|$, then the decrease in the injurer's expected cost due to the lower probability of trial in the event of an accident dominates the increase in his expected cost due to the higher probability of the judge appointing an expert: as a consequence, the injurer's level of care decreases. Conversely, if $\left|\frac{\partial F}{\partial \hat{\Delta}} \frac{\partial \hat{\Delta}}{\partial p}\right|$ is high enough compared to $\left|\frac{\partial G}{\partial \hat{L}} \frac{\partial \hat{L}}{\partial p}\right|$, then the injurer's level of care increases.

\subsection{Second instrument: the non-monetary cost of an expertise for the judge}

Proposition 2. An increase in $k$ increases the proportion of victims who file a lawsuit, and has an ambiguous effect on the injurer's level of care.

Proof. The proof is very similar to that for proposition 1. We know from the proof of proposition 1 that the threshold $\hat{L}$ is the solution of (10) and that $\frac{\partial U_{v}}{\partial \hat{L}}>0$. Moreover, we have:

$$
\frac{\partial U_{v}}{\partial k}=\frac{\partial F}{\partial \hat{\Delta}} \frac{\partial \hat{\Delta}}{\partial k}\left[(p-q)(y(\hat{L})-\hat{L})+(1-\alpha) c_{e}\right]>0
$$

Thus, from the implicit function theorem, we have $\frac{\partial \hat{L}}{\partial k}<0$ : the number of cases going to trial increases with $k$. 
The cost the injurer minimizes is (13) and we know from the proof of proposition 1 that $\frac{\partial^{2} C_{i}}{\partial x^{2}}>0$. Moreover, we have:

$$
\frac{\partial^{2} C_{i}}{\partial x \partial k}=-\frac{\partial G}{\partial \hat{L}} \frac{\partial \hat{L}}{\partial k} \pi^{\prime}(x)\left[(1-F(\hat{\Delta})) \alpha c_{e}+\hat{L}\right]-\frac{\partial F}{\partial \hat{\Delta}} \frac{\partial \hat{\Delta}}{\partial k} \pi^{\prime}(x)(1-G(\hat{L})) \alpha c_{e}
$$

The sign of (17) is ambiguous: an increase in $k$ has an ambiguous effect on the injurer's level of care.

The intuitions are the following. When $k$ increases, the judge appoints an expert less often. Consequently, the expected compensation for the marginal victim increases while the expected cost of the expert testimony she incurs decreases, thus increasing the proportion of victims who sue in the event of an accident. Turning now to the effect of an increase in $k$ on the injurer's level of care, we find two opposing effects. On one side, an increases in $k$ increases the proportion of victims who sue, and thus the expected cost of a trial for the injurer. On the other side, it reduces the probability of the judge appointing an expert, and thus the expected cost of expert testimony when there is a trial. The overall effect on the expected cost of an accident for the injurer (and thus on his incentive to take care) is ambiguous. More formally, which effect dominates depends on the magnitude of $\left|\frac{\partial G}{\partial \hat{L}} \frac{\partial \hat{L}}{\partial k}\right|$ relative to $\left|\frac{\partial F}{\partial \hat{\Delta}} \frac{\partial \hat{\Delta}}{\partial k}\right|$. 


\subsection{Third instrument: the cost of expert testimony}

Proposition 3. An increase in $c_{e}$ decreases the proportion of victims who file a lawsuit, and has an ambiguous effect on the injurer's level of care.

Proof. The proof is very similar to that for proposition 1. We know from the proof of proposition 1 that the threshold $\hat{L}$ is the solution of (10) and that $\frac{\partial U_{v}}{\partial \hat{L}}>0$. Moreover, we have:

$$
\frac{\partial U_{v}}{\partial c_{e}}=-(1-F(\hat{\Delta}))(1-\alpha)<0
$$

Thus, from the implicit function theorem, we have $\frac{\partial \hat{L}}{\partial c_{e}}>0$ : the number of cases going to trial decreases with $c_{e}$.

The cost the injurer minimizes is (13) and we know from the proof of proposition 1 that $\frac{\partial^{2} C_{i}}{\partial x^{2}}>0$. Moreover, we have:

$$
\frac{\partial^{2} C_{i}}{\partial x \partial c_{e}}=-\frac{\partial G}{\partial \hat{L}} \frac{\partial \hat{L}}{\partial c_{e}} \pi^{\prime}(x)\left[(1-F(\hat{\Delta})) \alpha c_{e}+\hat{L}\right]+\pi^{\prime}(x)(1-G(\hat{L}))(1-F(\hat{\Delta})) \alpha
$$

The sign of (19) is ambiguous: an increase in $c_{e}$ has an ambiguous effect on the injurer's level of care.

The intuitions are the following. First, a higher $c_{e}$ increases the expected cost of the expertise borne by the victim in the event of an accident, decreasing her incentive to sue. Second, like an increase in $k$, an increase in $c_{e}$ has two opposing effects. It directly increases the expected cost of a trial for the injurer. However, it also increases this cost for the victim, and thus it 
reduces the number of lawsuits filed. The overall effect on the injurer's cost and thus on his level of care is ambiguous.

Although this instrument is not discussed in the report of the committee on judicial expert appraisals (2011), we can show that one way to unambiguously increase the accessibility to the courts for victims, while increasing the injurer's level of care, is to increase the share of the expert testimony cost borne by the injurer $(\alpha)$.

\section{$5 \quad$ Public policy implications}

In this section, we start by defining the socially optimal level of care. We then discuss some policy implications of our model.

The socially optimal level of care minimizes the total expected cost of the potential injurer and victims. This total expected cost is the sum of the injurer's cost of care, the expected cost of expertise, and the expected harm:

$$
C_{s}=c(x)+\pi(x)\left[(1-G(\hat{L}))(1-F(\hat{\Delta})) c_{e}+\int_{0}^{\bar{L}} L d G(L)\right]
$$

Before determining the socially optimal level of precaution, note that (20) differs from (8) on two points. First, the objective of the policy maker is to minimize the total expected cost of the expert testimony, and not just the share $\alpha$ incurred by the injurer. Second, the policy 
maker takes into account the total expected harm in the event of an accident, and not just the expected compensation in the event of a trial.

We have omitted the expected utility of judges in this total expected cost. Indeed, we would like to have a total expected cost function which is an unweighted sum of the expected costs borne by the potential injurer and victims, as is generally done in the literature (see for example Gravelle, 1990). However, if we add the expected utility of judges to this total expected cost, additional effects to those highlighted below appear. More specifically, an increase in $k$ (or an increase in $p$ ) has an ambiguous effect on the expected utility of judges. ${ }^{20}$

The socially optimal level of care of the injurer, noted $x^{s}$, is the solution of:

$$
\frac{\partial C_{s}}{\partial x}=c^{\prime}\left(x^{s}\right)+\pi^{\prime}\left(x^{s}\right)\left[(1-G(\hat{L}))(1-F(\hat{\Delta})) c_{e}+\int_{0}^{\bar{L}} L d G(L)\right]=0
$$

It is straightforward to show that $\frac{\partial^{2} C_{s}}{\partial x^{2}}>0$. The marginal social cost is strictly lower than the private marginal cost of an increase in the injurer's level of care (and thus his level of

\footnotetext{
${ }^{20}$ To be even more specific, if $k$ increases, fewer judges appoint experts (indirectly reducing the nonmonetary cost of expertise for judges), and those who appoint an expert obtain lower expected utility from appointing one (the direct effect of an increase in $k$ ). Moreover, the number of suits filed increases (and thus the expected utility of the judge increases, since this expected utility is always positive as we have defined it), while the injurer's level of care (and thus the number of cases which may be filed and bring a positive utility to judges) varies ambiguously. The overall effect on the expected utility of judges is ambiguous. The reasoning is similar for $p$.
} 
care is too low) if and only if:

$$
\begin{aligned}
& \frac{\partial C_{s}}{\partial x}=c^{\prime}(x)+\pi^{\prime}(x) {\left[(1-G(\hat{L}))(1-F(\hat{\Delta})) c_{e}+\int_{0}^{\bar{L}} L d G(L)\right] } \\
&<\frac{\partial C_{i}}{\partial x}=c^{\prime}(x)+\pi^{\prime}(x)(1-G(\hat{L}))\left[(1-F(\hat{\Delta})) \alpha c_{e}+y(\hat{L})\right]
\end{aligned}
$$

This condition, after simplification, is equivalent to:

$$
(1-G(\hat{L}))(1-F(\hat{\Delta}))(1-\alpha) c_{e}+\int_{0}^{\hat{L}} L d G(L)>0
$$

First, the potential injurer only bears a share $\alpha$ of the cost of the expert testimony: he does not internalize all the cost. Second, the expected compensation the injurer has to pay to the victim is less than the total expected harm. These two effects encourage the injurer to choose too low a level of care.

Proposition 4. The injurer's level of care is lower than the level of care which minimizes the total expected cost $\left(C_{s}\right)$.

Proof. The proof is in the text.

This proposition implies that $\frac{\partial C_{s}}{\partial x^{*}}<0$. Thus, one objective of the policy maker should be to increase the injurer's level of care. However, as we show below, there is often a trade-off between this increase in the injurer's level of care and the minimization of the expected cost of trials in the event of an accident (which depends on the proportion of victims who sue and on the decisions of judges whether or not to appoint an expert). This trade-off may be inter- 
preted as an ex ante (increasing the injurer's level of care before an accident occurs) versus ex post (decreasing the expected cost of trials after an accident has occurred) perspective. We now discuss the effects of the different instruments highlighted in the introduction on the total expected $\operatorname{cost} C_{s}$, and make some public policy recommendations.

First instrument: the quality of expert testimony $(p)$. The policy maker should be able to increase the quality of expert testimony by imposing more stringent criteria for the registration of an expert on a certified public list. This measure may be combined with an increase in the fees of experts so as to have enough experts registered on these lists, but also in order to incentivize them to make a higher effort. The policy maker may also try to facilitate the reimbursement of their costs, to increase the time available for experts to conduct their investigations and write their reports. Moreover, encouraging the judge to conduct further investigations on his side to supplement those of the expert may also be a way to increase or decrease the expert's effort, and thus to increase or decrease the quality of the decision-making, as shown by Lambert and Oytana (2016). Finally, the policy maker may be able to increase the quality of expert testimony by providing common training to accredited experts, and by establishing scorecards for each of them. Note that all the reforms proposed above may entail additional costs (which may lead to an increase in $k$ and/or $c_{e}$ ) that we do not directly take into account in the model. The policy maker has to be aware of these costs when deciding whether or not to apply these proposals. 
In our model, the effect of an increase in $p$ on the total expected cost is:

$$
\frac{\partial C_{s}}{\partial p}=\frac{\partial C_{s}}{\partial G} \frac{\partial G}{\partial \hat{L}} \frac{\partial \hat{L}}{\partial p}+\frac{\partial C_{s}}{\partial F} \frac{\partial F}{\partial \hat{\Delta}} \frac{\partial \hat{\Delta}}{\partial p}+\frac{\partial C_{s}}{\partial x^{*}} \frac{\partial x^{*}}{\partial p}
$$

The first two terms represent the effect of an increase in $p$ on the expected cost of trials, respectively via the choice of victims to sue or not, and via the judge's decision whether or not to appoint an expert. The third term is the effect of $p$ on the injurer's level of care.

As we have shown in proposition 1 , the effect of $p$ on the injurer's level of care is ambiguous. More specifically, the sign of this effect depends on the sensitivity of the proportion of victims who sue according to $p$ (measured by $\left|\frac{\partial G}{\partial \hat{L}} \frac{\partial \hat{L}}{\partial p}\right|$ ), with respect to the sensitivity of the probability with which the judge appoints an expert (measured by $\left.\left|\frac{\partial F}{\partial \hat{\Delta}} \frac{\partial \hat{\Delta}}{\partial p}\right|\right)$. To illustrate, let us assume that $\left|\frac{\partial G}{\partial \hat{L}} \frac{\partial \hat{L}}{\partial p}\right|$ is high enough compared with $\left|\frac{\partial F}{\partial \hat{\Delta}} \frac{\partial \hat{\Delta}}{\partial p}\right|$, such that expression (15) is positive (and therefore $\frac{\partial x^{*}}{\partial p}<0$ ) and $\frac{\partial C_{s}}{\partial G} \frac{\partial G}{\partial \hat{L}} \frac{\partial \hat{L}}{\partial p}+\frac{\partial C_{s}}{\partial F} \frac{\partial F}{\partial \hat{\Delta}} \frac{\partial \hat{\Delta}}{\partial p}<0$. In this case, there exists a trade-off for the policy maker between reducing the proportion of victims who sue in the event of an accident, and giving the injurer the incentive to take care. If the policy maker's objective is mainly to increase the injurer's level of care (this is the case if $c_{e}$ is sufficiently low relative to the expected harm for instance), then he should reduce $p$. Conversely, if he seeks to reduce the proportion of victims who sue in the event of an accident, then an increase in $p$ allows him to do that. However, if $\left|\frac{\partial G}{\partial \hat{L}} \frac{\partial \hat{L}}{\partial p}\right|$ is sufficiently low relative to $\left|\frac{\partial F}{\partial \hat{\Delta}} \frac{\partial \hat{\Delta}}{\partial p}\right|$, such that expression (15) is negative (and therefore $\frac{\partial x^{*}}{\partial p}>0$ ) and $\frac{\partial C_{s}}{\partial G} \frac{\partial G}{\partial \hat{L}} \frac{\partial \hat{L}}{\partial p}+\frac{\partial C_{s}}{\partial F} \frac{\partial F}{\partial \hat{\Delta}} \frac{\partial \hat{\Delta}}{\partial p}>0$, these recommendations are reversed: an increase in $p$ narrows the gap between the injurer's 
level of care and the socially optimal one, and a decrease in $p$ lowers the expected cost of expertise in case of an accident (the probability of the judge appointing an expert is lower). ${ }^{21}$

\section{Second instrument: the non-monetary cost of an expertise for the judge $(k)$. In}

our model, this cost $k$ represents the non-monetary cost for the judge to appoint an expert.

Indeed, for the judge, an expert testimony implies making an extra effort in order to select the expert, monitor the expertise procedure and read and interpret the report. Moreover, an expert testimony may increase the time needed before a decision is made by the judge. One way to reduce this cost $k$ may be to harmonize and facilitate the rules governing the selection and the appointment of experts. It is also possible to enhance the lists of registered experts by developing a national database in order to improve the evaluation and monitoring of experts, and to make it easier for the judge to find a competent expert. Another measure may be to provide training for judges to facilitate their monitoring and interpretation work. Last but not least, an additional suggestion is to normalize the presentation of the experts' reports to improve their readability for the judge.

The reasoning when $k$ increases is very similar to that we made previously for a decrease in the quality of the expertise $(p)$. There exists a trade-off between incentivizing the injurer to take more precautions, and reducing the expected cost of litigation in the event of an accident (respectively the ex ante and ex post perspectives). More specifically, if $\left|\frac{\partial G}{\partial \hat{L}} \frac{\partial \hat{L}}{\partial k}\right|$

\footnotetext{
${ }^{21}$ For intermediate values of $\left|\frac{\partial G}{\partial \hat{L}} \frac{\partial \hat{L}}{\partial p}\right|$ and $\left|\frac{\partial F}{\partial \hat{\Delta}} \frac{\partial \hat{\Delta}}{\partial p}\right|$, there may exist situations in which the policy maker is able to simultaneously increase the injurer's level of care, while reducing the expected cost of trials in the event of an accident.
} 
is sufficiently high relative to $\left|\frac{\partial F}{\partial \hat{\Delta}} \frac{\partial \hat{\Delta}}{\partial k}\right|$, an increase in $k$ allows the policy maker to increase the injurer's level of care, but at the cost of a larger probability of trial in the event of an accident. Conversely, if $\left|\frac{\partial G}{\partial \hat{L}} \frac{\partial \hat{L}}{\partial k}\right|$ is sufficiently low relative to $\left|\frac{\partial F}{\partial \hat{\Delta}} \frac{\partial \hat{\Delta}}{\partial k}\right|$, an increase in $k$ reduces the probability of the judge appointing an expert (and thus the expected cost of expert testimony), but at the cost of a decrease in the injurer's level of care.

Third instrument: the cost of expert testimony $\left(c_{e}\right)$. In order to reduce the (monetary) cost of expert testimony borne by the parties, some concrete suggestions are to use more often expert's consultations and observations, ${ }^{22}$ which are faster and cheaper than a full expertise proceeding. Another suggestion may be to limit the use of expert testimony to the cases in which the stake is above a certain threshold. ${ }^{23}$

The effect of an increase in $c_{e}$ on the total expected cost is:

$$
\frac{\partial C_{s}}{\partial c_{e}}=\frac{\partial C_{s}}{\partial G} \frac{\partial G}{\partial \hat{L}} \frac{\partial \hat{L}}{\partial c_{e}}+\frac{\partial C_{s}}{\partial x^{*}} \frac{\partial x^{*}}{\partial c_{e}}+\pi(x)(1-G(\hat{L}))(1-F(\hat{\Delta}))
$$

Increasing the cost of an expert testimony has the direct effect of increasing the total expected cost of trials (this direct effect corresponds to the third term in (25)). However, it indirectly decreases the probability of a trial in the event of an accident, and thus the expected cost of trials (the first term in (25)). Moreover, from expression (19) and the implicit

\footnotetext{
${ }^{22}$ Note however that requiring an expert's consultation or observation instead of a full expertise may have a perverse effect on the quality of the expertise $(p)$.

${ }^{23}$ In our model, if $\bar{L}$ is sufficiently low, then the objective of the policy maker is mainly to reduce the expected cost of trials, and it may be optimal to forbid the use of an expertise.
} 
function theorem, we know that an increase in $c_{e}$ has an unambiguously positive effect on the injurer's level of care (i.e. $\frac{\partial x^{*}}{\partial c_{e}}>0$ ) only if $\left|\frac{\partial G}{\partial \hat{L}} \frac{\partial \hat{L}}{\partial c_{e}}\right|$ is sufficiently low. In this case, and if the policy maker seeks to increase the injurer's level of care, then an increase in $c_{e}$ allows him to do that. Conversely, if his main objective is to decrease the expected cost of expertise in the event of an accident, then he should decrease $c_{e}$.

Other instruments. An interesting alternative to an increase (or a decrease) in the cost of expertise is to add an administrative cost of litigation for the parties. Even if we have not explicitly modeled them in order to keep the model as simple as possible, it is possible to guess what the effect of a change in these litigation costs will be. In the context of our model, an increase in the litigation cost borne by the injurer will increase his level of care, while an increase in the litigation cost borne by the victim may reduce the proportion of victims who sue in the event of an accident, and thus reduce the expected costs of trials when an accident occurs (albeit at the cost of a lower level of care on the part of the injurer).

An interesting alternative, in order to close the gap between the injurer's level of care and the socially optimal level of care, may be to increase the share of the expertise cost borne by the injurer $(\alpha)$. However, the use of this instrument again imposes a trade-off for the policy maker between increasing the injurer's level of care and reducing the expected cost of trials. To illustrate this consider the extreme cases in which $\alpha=1$ and $\alpha=0$. First, if $\alpha=1$, all victims decide to sue and the injurer's level of care is $x_{a}^{*}$. This level of care is socially optimal. 
However, this cost-sharing rule does not necessarily minimize the total expected cost, because the trial costs are then maximum since all victims litigate. Conversely, if $\alpha=0$ and if $c_{e}$ is sufficiently high, then no victim sues. On one side, this solution minimizes the expected cost of trials, but on the other side, the probability of an accident (and therefore the probability of harm) is maximum. More generally, if the policy maker seeks to close the gap between the injurer's level of care and the level that minimizes the total expected $\operatorname{cost} C_{s}$, then he should increase $\alpha$ (the injurer internalizes a greater part of the cost of expertise). However, if the policy maker seeks to reduce the expected cost of a trial by reducing the proportion of victims who sue, then he should reduce $\alpha$ (adopt a more pro-defendant cost-sharing rule).

\section{Settlement}

So far, we have ignored the possibility for the injurer and the victim to settle. We show in this section that adding a settlement stage before the victim decides to sue does not substantially change our results. We proceed in two steps. In a first subsection, we show in a simplified version of our model that an agreement between the parties is not always possible. In a second subsection, we show that even if an agreement is attainable, most of our main results remain valid.

\subsection{The possibility of settlement}

In this subsection, we try to answer the following question: is the injurer always willing to make an offer in order to settle? To investigate this question, we add a settlement stage 
before the victim chooses whether or not to sue. In the same vein as Bebchuk (1984) or Hylton (2002), we consider a settlement stage in which the less informed party (the injurer in our model) makes a take-it-or-leave-it offer to the party with private information (the victim). We aim to determine the condition under which the injurer will actually have an interest in making an offer which may be accepted with a positive probability by the victim.

Without loss of generality, we use a simplified version of the model presented in section 2 . We assume that the judge systematically appoints an expert and that there are only two types of victims. With probability $a \in(0,1)$, the victim is type $L=L_{l}$ (low harm). With probability $1-a$, the victim is type $L=L_{h}$ (high harm). Moreover, we assume that the offer made by the injurer is publicly observable.

We focus thereafter on values of the parameters such that, if the injurer does not make an offer (or equivalently makes an offer $s=0$ ), only the victims of type $L_{h}$ sue. In other words, the threat of a lawsuit from a victim $L_{l}$ is not credible if $s=0$. More formally, we assume that the following conditions hold:

$$
\begin{array}{r}
L_{h}>(1-\alpha) c_{e} \\
p L_{l}+(1-p) L_{h}<(1-\alpha) c_{e}
\end{array}
$$

Inequality (26) is the incentive constraint of the victim of type $L_{h}$. If the injurer does not make an offer, this victim prefers to sue, because her compensation $\left(L_{h}\right)$ is superior to her 
expected cost of trial $\left((1-\alpha) c_{e}\right)$. Note that, even if the judge does not observe the victim's type, he acts as a Bayesian decision-maker and thus makes a decision which is correct on average. In this simplified version of the model, this decision is $y=L_{h}$ because, in the separating equilibrium we focus on, and when there is no offer from the injurer, a victim of type $L_{l}$ never files a lawsuit. Inequality (27) is the incentive constraint of a victim of type $L_{l}$. This condition means that a victim of type $L_{l}$ obtains a lower payoff in the event of deviation from the separating equilibrium (i.e. if she decides to sue). Conditions (26) and (27) can be met simultaneously, since the payoff from filing a lawsuit for a victim of type $L_{l}$ is inferior to the payoff of doing so for a victim of type $L_{h}$, (because the judge observes the harm suffered by a victim with positive probability $p)$, while the cost of a trial is $(1-\alpha) c_{e}$ for both types.

Let us turn now to the case in which the injurer makes an offer. We use the intuitive criterion (Cho and Kreps, 1987): in the equilibrium in which all victims are better off accepting the offer, if the judge observes a deviation by a victim who rejects the offer, his out-of-equilibrium beliefs are that this victim is type $L_{h}$ with probability one. Thus, if the injurer decides to make a credible offer $s$ (i.e. an offer accepted with a positive probability by the victim), the optimal offer is:

$$
s^{*}=L_{h}-(1-\alpha) c_{e}
$$

The injurer offers the lowest amount possible such that a victim of type $L_{h}$ does not litigate. Note that an offer higher than $s^{*}$ is not optimal for the injurer, since this is more costly for 
him, while it does not decrease the probability of trial (all victims already accept the offer $s^{*}$ at the equilibrium, so there is no trial). Moreover, if the injurer makes a credible offer lower than $s^{*}$, only the victims of type $L_{l}$ accept it. This is not worthwhile for the injurer, since the decision to sue for these victims is not a credible threat at the equilibrium without offer.

If the injurer does not make an offer, then his expected costs (after an accident has occurred) are given by $(1-a)\left(L_{h}+\alpha c_{e}\right)$. Thus, the injurer prefers to make an offer $s^{*}$ rather than none if the following condition holds:

$$
s^{*}<(1-a)\left(L_{h}+\alpha c_{e}\right)
$$

After substituting $s^{*}$ with (28) and some manipulations, this expression can be rewritten as:

$$
c_{e}>\frac{a L_{h}}{1-a \alpha}
$$

Intuitively, the benefit of making an offer $s^{*}$ for the injurer is that he avoids the cost of a trial. However, the cost of making this offer is that the injurer has to pay $s^{*}$ even to those victims of type $L_{l}$ for whom a lawsuit, absent any offer, is not a credible threat. More specifically, the interpretation of condition (30) is that it is optimal for the injurer to make the offer $s^{*}$ if $c_{e}$ is sufficiently high, and if $\alpha, L_{h}$, and $a$ are sufficiently low. ${ }^{24}$ Consequently,

\footnotetext{
${ }^{24}$ If we assume that the cost of filing a lawsuit is positive, and for some values of the parameters, a mixedstrategy equilibrium exists in which a victim of type $L_{l}$ decides to sue, and the defendant decides to settle, with probabilities strictly between 0 and 1 (while a victim of type $L_{h}$ always files a lawsuit).
} 
it is not always interesting for the injurer to make an offer. This conclusion holds in the more complete version of the model presented in section 2 .

\subsection{The settlement amount}

Let us now see what happens if it is actually optimal for the injurer to make an offer. In order to do so, we go back to the more general model of section 2 , which we extend to allow for the possibility that the injurer makes a take-it-or-leave-it offer before the victim decides whether or not to sue. We focus on the separating equilibrium in which only a victim who has suffered a harm which lies below a threshold such that $L \leq \hat{L}^{\prime}$ decides to accept the injurer's offer, while a victim $L>\hat{L}^{\prime}$ decides to go to trial. This threshold is defined by the following equation:

$$
F(\hat{\Delta})\left(q \hat{L}^{\prime}+(1-q) y\left(\hat{L}^{\prime}\right)\right)+(1-F(\hat{\Delta}))\left(p \hat{L}^{\prime}+(1-p) y\left(\hat{L}^{\prime}\right)-(1-\alpha) c_{e}\right)=s
$$

By reasoning as in section 4, it is possible to show (for a given offer $s$ ) that the proportion of victims who bring a lawsuit in the event of an accident decreases with $p, c_{e}$, and $s$, and increases with $\alpha$ and $k$. In other words, our comparative statics results for the threshold $\hat{L}^{\prime}$ are qualitatively the same as the ones we find in section 4 for the threshold $\hat{L}$.

In the event of an accident, the expected cost borne by the injurer is given by:

$$
C_{i, o}=G\left(\hat{L}^{\prime}\right) s+\left(1-G\left(\hat{L}^{\prime}\right)\right)\left[y\left(\hat{L}^{\prime}\right)+(1-F(\hat{\Delta})) \alpha c_{e}\right]
$$


The first order condition for the injurer's choice of his offer is:

$$
\frac{\partial C_{i, o}}{\partial s}=G\left(\hat{L}^{\prime}\right)+\frac{\partial G}{\partial \hat{L}^{\prime}} \frac{\partial \hat{L}^{\prime}}{\partial s} s-\frac{\partial G}{\partial \hat{L}^{\prime}} \frac{\partial \hat{L}^{\prime}}{\partial s}\left(\hat{L}^{\prime}+(1-F(\hat{\Delta})) \alpha c_{e}\right)=0
$$

The first two terms are the marginal cost of an increase in $s$, respectively via the direct effect of the increase in the offer amount, and the indirect effect via the increase in the probability that this higher offer is accepted. The third term is the marginal benefit of an increase in $s$ for the injurer, via the decrease in the probability of a trial in the event of an accident (and thus a decrease in the expected compensation and expertise cost). This expression is equivalent to expression (6) in Bebchuk (1984).

How does the expected cost of an accident for the injurer (given by (32)) vary with $p, \alpha, k$, and $c_{e}$ ? From the envelope theorem, and after some manipulations, the effect of an increase in $p$ on this expected cost is:

$$
\frac{\partial C_{i, o}}{\partial p}=\frac{\partial G}{\partial \hat{L}^{\prime}} \frac{\partial \hat{L}^{\prime}}{\partial p}\left(s-\left(\hat{L}^{\prime}+(1-F(\hat{\Delta})) \alpha c_{e}\right)\right)-\frac{\partial F}{\partial \hat{\Delta}} \frac{\partial \hat{\Delta}}{\partial p}\left(1-G\left(\hat{L}^{\prime}\right)\right) \alpha c_{e}
$$

We find that, as was the case without the possibility for the parties to settle, the effect of an increase in $p$ on the expected cost of the injurer in the event of an accident is ambiguous and depends on the sensitivity of the probability that the victim accepts the offer according to $p$ (measured by $\left.\left|\frac{\partial G}{\partial \hat{L}^{\prime}} \frac{\partial \hat{L}^{\prime}}{\partial p}\right|\right)$, relative to the sensitivity of the probability with which the judge appoints an expert (measured by $\left.\left|\frac{\partial F}{\partial \hat{\Delta}} \frac{\partial \hat{\Delta}}{\partial p}\right|\right)$. This result is similar to the one obtained in the 
absence of settlement. Following the same reasoning for the other parameters (for the sake of brevity, we do not give the details), we find that once again our results are qualitatively similar to those of section 4 .

Is the total expected cost lower when the injurer makes an offer? Since we do not have an explicit solution for the equilibrium settlement offer, it is difficult to give a definite answer to this question. On one side, if the parties manage to settle, then it lowers the expected cost of trials in the event of an accident, which is socially desirable. On another side, because these costs are lower and the injurer tries to settle only if it reduces his expected costs in the event of an accident, his level of care will be lower. ${ }^{25}$

\section{Conclusion}

In this paper, we have presented an extension of an otherwise standard unilateral care model under strict liability to include the possibility for a judge to appoint a neutral expert. More specifically, we have focused on the impact of three public policy instruments (the quality of expert testimony, the judge's accessibility to the expertise procedure, the reduction of cost associated with the expertise proceedings) on the level of care of a potential injurer, and on the expected cost of trials. Our model has allowed us to make some public policy recommendations, assuming that the policy maker's objective is to minimize the total expected cost (the sum of the injurer's cost of care, the expected harm suffered by victims and the

\footnotetext{
${ }^{25}$ We can conjecture that, in general, the result stating that his level of care is lower than what is socially optimal may be extended to the case where the injurer has the possibility to settle.
} 
expected cost of trials).

We have shown that the injurer's level of care is lower than the level that minimizes the total expected cost. However, it is difficult to make clear-cut public policy recommendations. Indeed, there often exists a trade-off for the policy maker between on one side incentivizing the injurer to choose a higher level of care, and on the other side reducing the expected cost of trials (or the expected cost of expertise in our model) after an accident occurred. This trade-off exists for example when the policy maker is acting on the quality of expert testimony. The overall impact of an increase in this quality depends to a large extent on the magnitude of the effect on the proportion of victims who sue, when compared to the effect on the probability that the judge will appoint an expert. Which effect dominates may alter the pertinence of an increase (or a decrease) in the quality of expert testimony, notwithstanding the cost of such a measure. Similar countervailing effects exist regarding the non-monetary cost of an expert testimony for the judge, and the cost of expert testimony incurred by the parties. Thus, the policy maker should be cautious when applying the different public policy recommendations suggested in the report of the committee on judicial expert appraisals (2011).

Our model can be extended in various directions. A first possible extension would be to consider a negligence rule rather than strict liability. In this context, the expert may bring evidence to help the judge determine whether the injurer has complied with the due-care 
standard, and not only evidence on the amount of damages. A second possible extension could be to consider a bilateral care model. A third possible extension would be to explicitly model the delegation relationship between the judge and the expert. However, to do that, one has to think carefully about the specific objectives pursued both by the judge and the expert. 


\section{References}

Bebchuk, L. (1984). Litigation and settlement under imperfect information. The Rand Journal of Economics, 15(3):404-415.

Block, M., Parker, J., Vyborna, O., and Dusek, L. (2000). An experimental comparison of adversarial versus inquisitorial procedural regimes. American Law and Economics Review, $2: 170-194$.

Bourjade, S. and Jullien, B. (2011). The roles of reputation and transparency on the behavior of biased experts. The RAND Journal of Economics, 42(3):575-594.

Cecil, J. and Willging, T. (1993). Court-appointed experts: Defining the role of experts appointed under Federal Rule of Evidence 706. Federal Judicial Center.

Cho, I.-K. and Kreps, D. M. (1987). Signaling games and stable equilbiria. The Quarterly Journal of Economics, 102(2):179-221.

Crawford, V. and Sobel, J. (1982). Strategic information transmission. Econometrica, 50(6):1431-1452.

Deffains, B. and Demougin, D. (2008). The inquisitorial and the adversarial procedure in a criminal court setting. Journal of Institutional and Theoretical Economics, 164(1):31-43.

Dewatripont, M. and Tirole, J. (1999). Advocates. Journal of Political Economy, 107(1):139. 
Farrell, J. (1993). Meaning and credibility in cheap-talk games. Games and Economic Behavior, 5(4):514-531.

Froeb, L. and Kobayashi, B. (2001). Evidence production in adversarial vs. inquisitorial regimes. Economics Letters, 70(2):201-212.

Gravelle, H. S. E. (1990). Rationing trials by waiting: Welfare implications. International Review of Law and Economics, 10(3):255-270.

Gromb, D. and Martimort, D. (2007). Collusion and the organization of delegated expertise. Journal of Economic Theory, 137:271-299.

Hylton, K. N. (1990). Costly litigation and legal error under negligence. Journal of Law, Economics, and Organization, 6(2):433-452.

Hylton, K. N. (2002). An asymmetric-information model of litigation. International Review of Law and Economics, 22(2):153-175.

Krishna, V. and Morgan, J. (2001). A model of expertise. The Quarterly Journal of Economics, 116(2):747-775.

Lambert, E.-A. and Oytana, Y. (2016). Judicial expertise and effort decisions. Working paper.

Li, M. (2010). Advice from multiple experts: A comparison of simultaneous, sequential, and hierarchical communication. The B.E. Journal of Theoretical Economics, 10(1):1-24. 
Mandel, M. J. (1999). Going for the gold: Economists as expert witnesses. Journal of Economic Perspective, 13(2):113-120.

Morris, S. (2001). Political correctness. Journal of Political Economy, 109(2):231-265.

Ottaviani, M. and Sorensen, P. N. (2006). Reputational cheap talk. The Rand Journal of Economics, 37:155-175.

Oytana, Y. (2014). The judicial expert in a two-tier hierarchy. Journal of Institutional and Theoretical Economics, 170(3):537-570.

Palumbo, G. (2001). Trial procedures and optimal limits on proof-taking. International Review of Law $\&$ Economics, 21(3):309-327.

Palumbo, G. (2006). Optimal duplication of effort in advocacy systems. Journal of Economic Behavior \& Organization, 60(1):112-128.

Parisi, F. (2002). Rent-seeking through litigation: Adversarial and inquisitorial systems compared. International Review of Law \& Economics, 22(2):193-216.

Patterson, M. R. (1999). Conflicts of interest in scientic expert testimony. William \& Mary Law Review, 33(4):1313-1394.

Png, I. P. L. (1986). Optimal subsidies and damages in the presence of judicial error. International Review of Law and Economics, 6(1):101-105.

Polinsky, A. M. and Shavell, S. (1989). Legal error, litigation, and the incentive to obey the law. Journal of Law, Economics \& Organization, 5:99-108. 
Posner, R. (1999). The law and economics of the economic expert witness. Journal of Economic Perspective, 13(2):91-99.

Rubinfeld, D. L. and Polinsky, A. M. (1988). The deterrent effects of settlements and trials. International Review of Law and Economics, 8(1):109-116.

Shavell, S. (1982). The social versus the private incentive to bring suit in a costly legal system. Journal of Legal Studies, 11:333-339.

Shin, H. S. (1994). The burden of proof in a game of persuasion. Journal of Economic Theory, 64(1):253-264.

Sobel, J. (1985). A theory of credibility. Review of Economic Studies, 52(4):557-573.

Thornton, R. and Ward, J. (1999). The economist in tort litigation. Journal of Economic Perspective, 13(2):101-112.

Tomlin, J. T. and Cooper, D. (2008). Expert testimony, Daubert, and the determination of damages. Review of Law \& Economics, 4(1):11.

Turner, J. A. (2006). Going after the 'hired guns': Is improper expert witness testimony unprofessional conduct or the negligent practice of medicine? Pepperdine Law Review, 40(2):275-309.

Yee, K. (2008). Dueling experts and imperfect verification. International Review of Law $\mathcal{E}$ Economics, 28(4):246-255. 